\title{
Impact of subglottic secretion drainage on microaspiration in critically ill patients: a prospective observational study
}

\author{
Guillaume Millot ${ }^{1}$, Pauline Boddaert ${ }^{1}$, Erika Parmentier-Decrucq ${ }^{1}$, Aurore Palud ${ }^{1}$, Malika Balduyck ${ }^{2,3}$, \\ Patrice Maboudou $^{3}$, Farid Zerimech ${ }^{3}$, Frédéric Wallet ${ }^{4}$, Sébastien Preau ${ }^{1,5,6}$, Saad Nseir ${ }^{1,5,6}$ \\ ${ }^{1} \mathrm{CHU}$ Lille, Critical Care Center, Lille, France; ${ }^{2}$ Univ. Lille, Pharmacology Faculty, Lille, France; ${ }^{3} \mathrm{CHU}$ Lille, Centre de Biologie et de Pathologie, \\ Lille, France; ${ }^{4} \mathrm{CHU}$ Lille, Laboratory of Microbiology, Lille, France; ${ }^{5}$ Univ. Lille, U995-LIRIC-Lille Inflammation Research International Center, \\ Lille, France; ${ }^{6}$ Inserm, U995, Lille, France \\ Contributions: (I) Conception and design: A Palud, S Nseir; (II) Administrative support: None; (III) Provision of study materials or patients: E \\ Parmentier-Decrucq, A Palud, S Preau, S Nseir; (IV) Collection and assembly of data: G Millot, P Boddaert, A Palud, M Balduyck, P Maboudou, F \\ Zerimech, F Wallet; (V) Data analysis and interpretation: G Millot, P Boddaert, E Parmentier-Decrucq, A Palud, S Nseir; (VI) Manuscript writing: \\ All authors; (VII) Final approval of manuscript: All authors. \\ Correspondence to: Prof. Saad Nseir. CHU Lille, Centre de Réanimation, F-59000 Lille, France. Email: s-nseir@chru-lille.fr.
}

\begin{abstract}
Background: Microaspiration is a major factor in ventilator-associated pneumonia (VAP) pathophysiology. Subglottic secretion drainage (SSD) aims at reducing its incidence.

Methods: Single-center prospective observational study, performed in a French intensive care unit (ICU) from March 2012 to April 2013, including adult patients mechanically ventilated for at least 24 hours divided in two groups: patients in the SSD group intubated using tracheal tubes allowing SSD and patients in the control group intubated with standard tracheal tubes. Pepsin and salivary amylase concentrations were measured for 24 hours in all tracheal aspirates. Primary objective was to determine the impact of SSD on gastric or oropharyngeal microaspiration using pepsin or amylase concentration in tracheal aspirates.

Results: Fifty-five patients were included in the SSD group and 45 in the control group. No difference was found between groups regarding the incidence of microaspiration defined as at least one tracheal aspirate positive for either pepsin or amylase [49 (89\%) vs. 37 (82\%), $\mathrm{P}=0.469$ ]. Percentage of patients with VAP [16 (29\%) vs. 11 (24\%), $\mathrm{P}=0.656$, ventilator-associated tracheobronchitis (VAT) [7 (13\%) vs. 4 (9\%), P=0.750] or early airway colonization [15 (35\%) vs. 8 (18\%), $\mathrm{P}=0.219]$ were not significantly different in study groups.

Conclusions: SSD did not reduce the incidence of microaspiration, VAP, VAT or airway colonization in this observational study.
\end{abstract}

Keywords: Ventilator-associated pneumonia (VAP); subglottic secretion drainage (SSD); microaspiration

Submitted Oct 03, 2018. Accepted for publication Oct 09, 2018.

doi: $10.21037 /$ atm.2018.10.44

View this article at: http://dx.doi.org/10.21037/atm.2018.10.44

\section{Introduction}

Ventilator-associated pneumonia (VAP) is a major concern in intensive care units (ICU). VAP is the most common ICU-acquired infection, representing $30 \%$ to $50 \%$ of these infections (1). VAP has been shown to worsen patient outcome, with a reported mortality of $20 \%$ (2) and an attributable mortality of $10 \%$ to $30 \%$ (3). It has also been shown to increase the length of mechanical ventilation (MV), length of stay (4), and cost (5).

For these reasons, prevention, diagnosis and adequate treatment of VAP are priority goals in ICU patients. Several prevention strategies are recommended in international (6) and national (7) guidelines, implemented as "bundles": favoring non-invasive ventilation whenever possible, reducing sedation and neuromuscular blockade levels using sedation scales, early enteral nutrition initiation, regular 
monitoring of endotracheal tube cuff pressure, favoring orotracheal intubation whenever possible, and subglottic secretion drainage (SSD), at least every 8 hours, using adequate tracheal tubes.

Most of these prevention strategies aim to reduce airway colonization, a major mechanism in VAP pathophysiology. The presence of the tracheal tube allows two paths for bacterial airway colonization: endoluminal colonization, a consequence of the formation of a biofilm inside the endotracheal tube lumen about 60 hours after intubation; and extraluminal colonization, which is a consequence of the progression of contaminated secretions of oral and gastric origin accumulated above the endotracheal tube cuff. This latter path, called microaspiration (8), is believed to be the most frequently implied in VAP pathophysiology $(9,10)$.

The effectiveness of SSD in mechanically ventilated patients in the ICU has been evaluated by several randomized controlled studies and meta-analyses (11-17), with most of them concluding to a reduction of VAP incidence. However, no study to date has evaluated the impact of SSD on microaspiration.

The main objective of the present study was to assess the effectiveness of SSD in reducing the incidence of microaspiration in critically-ill patients requiring invasive MV.

\section{Methods}

This single-center, prospective, observational study was conducted in the Medical ICU of the University Hospital Center of Lille from March 2012 to April 2013.

For this strictly observational study, no approval was required from the local ethics committee. Patients or patients' proxy were informed of the patients' participation in the study and could refuse participating or withdraw from the study at any point.

\section{Patient population}

Patients 18 years of age or older who were admitted to our ICU, intubated and mechanically ventilated for more than 24 hours with an anticipated length of MV of at least 24 hours were included.

Exclusion criteria were: history of intubation within the last 6 months, intubation with a low volume high pressure tracheal cuff, patients whose tracheal cuff was inflated with water (which is a common practice for patients receiving hyperbaric oxygen therapy), patients ventilated using a tracheostomy at admission.

\section{Group attribution}

Patients were separated in two groups depending on the type of tracheal tube:

* The SSD group, consisting of patients with no tracheal tube at ICU admission, but later requiring tracheal intubation for MV. These patients were intubated using tracheal tubes allowing SSD, commonly used in our ICU (TaperGuard Evac ${ }^{\circledR}$, Mallinckrodt). Those tracheal tubes include a tapered polyvinyl chloride (PVC) cuff. Inner diameters were $7.5 \mathrm{~mm}$ for adult females and $8 \mathrm{~mm}$ for adult males. Intermittent SSD was performed by nurses every three hours using a syringe;

* The control group was composed of patients already intubated at ICU admission with a tracheal tube that did not allow SSD. All tracheal tubes in this group had a cylindrical PVC cuff.

Standard preventive measures for VAP were performed as usual in our ICU, including semi-recumbent position between $30^{\circ}$ and $45^{\circ}$, oral care, assessment of cuff pressure every 8 hours using a manometer to maintain a cuff pressure (Pcuff) as close to $25 \mathrm{cmH}_{2} \mathrm{O}$ as possible, minimal positive end-expiratory pressure (PEEP) of $5 \mathrm{cmH}_{2} \mathrm{O}$ whenever possible, hand hygiene, isolation precautions for patients colonized or infected with multidrug-resistant bacteria, and written antimicrobial therapy protocols.

\section{Data collection}

\section{Laboratory tests}

During the 24 hours following patient inclusion, all tracheal aspirates were collected in both groups, and conserved at temperature of $-20{ }^{\circ} \mathrm{C}$. Quantitative measurement of pepsin and the salivary isoenzyme of amylase were achieved using ELISA technique (18). Concentrations above $200 \mu \mathrm{g} / \mathrm{L}$ for pepsin and 1,685 IU/L for amylase were used to define positive samples (19). Laboratory technicians performing the measurements were blinded for patients' group.

Bacteriological examination of tracheal aspirate was performed twice a week, with a quantitative analysis performed with a threshold of $10^{3} \mathrm{CFU} / \mathrm{mL}$ to allow for detection of tracheobronchial tract bacterial colonization.

\section{Demographic data}

All demographic data were prospectively collected. The following data were collected at ICU admission: gender, age, simplified acute physiology score II (SAPS II) (20), 
McCabe (21) and logistic organ dysfunction (LOD) (22) score, medical history (diabetes mellitus, chronic obstructive pulmonary disorder (COPD), chronic heart failure, cirrhosis with a class B or C Child-Pugh score, end-stage chronic kidney disease requiring chronic hemodialysis, gastroesophageal reflux disease (GERD), chronic respiratory failure due to restrictive lung disease), patient location before ICU admission (home, hospital, another ICU), active infection at admission, recent antimicrobial treatment (during the last 3 months), main diagnosis at admission.

The following data were collected at patient inclusion: LOD score, tracheal tube characteristics (type, size, orotracheal or nasotracheal intubation).

\section{Follow-up data}

The following data were collected during the 24 hours following patient inclusion: enteral feeding volume, gastric residual volume, vomiting, use of gastroprokinetic agents, stress ulcer prophylaxis type (sucralfate or proton pump inhibitors), mean tracheal cuff pressure (Pcuff), Pcuff $<20 \mathrm{cmH}_{2} \mathrm{O}$, sedation, use of neuromuscular blocking drugs, Glasgow coma scale (GCS), Ramsay sedation scale, elevation of the head-of-bed, out-of-ICU patient transport, prone positioning, mean PEEP, MV mode [assist-control ventilation (ACV), bilevel positive airway pressure (BiPAP), pressure-support ventilation (PSV)]. The number of tracheal aspirates and subglottic secretion suctioning were also collected.

The following data were collected during the whole ICU stay: mortality, length of stay, VAP, VAT.

\section{Other definitions}

Gastric microaspiration was defined by the presence of pepsin at significant concentration $(200 \mu \mathrm{g} / \mathrm{L})$ in at least one tracheal aspirate. Oropharyngeal microaspiration was defined by the presence of salivary amylase at significant concentration $(>1,685 \mathrm{IU} / \mathrm{L})$ in at least one tracheal aspirate. Microaspiration, regardless of origin, was defined by the presence of pepsin or salivary amylase at significant concentrations in at least one tracheal aspirate. Tracheobronchial colonization was defined as a positive tracheal aspirate $\geq 10^{3} \mathrm{CFU} / \mathrm{mL}$. Pneumonia was defined according to ATS/IDSA guidelines (6) as a new or progressing radiological infiltrate associated with two of the following criteria: temperature $>38.5$ or $<36^{\circ} \mathrm{C}$, white blood cell count $>10$ or $<1.5 \mathrm{G} / \mathrm{L}$, purulent tracheal aspirates. Bacteriological confirmation was required, with a threshold of $10^{6} \mathrm{CFU} / \mathrm{mL}$ in tracheal aspirate or $10^{4} \mathrm{CFU} / \mathrm{mL}$ in BAL. VAP was defined as a pneumonia diagnosed 48 hours or more after intubation, with early VAP defined as a VAP occurring 2 to 5 days after intubation and late VAP defined as a VAP occurring $\geq 5$ days after intubation. Ventilator-associated tracheobronchitis (VAT) was defined as the association of (I) a temperature $>38^{\circ} \mathrm{C}$ without other explanation, (II) purulent tracheal aspirates, (III) positive ETA with a threshold of $10^{6}$ $\mathrm{CFU} / \mathrm{mL}$ and (IV) no radiological criteria for pneumonia. ICU-acquired infections other than VAP and VAT were defined using modified CDC criteria (23).

\section{Outcomes}

The primary outcome of this study was the percentage of patients with microaspiration.

The secondary outcomes were percentage of patients with microaspiration of gastric contents, microaspiration of oropharyngeal secretions, VAP, VAT, and tracheobronchial colonization.

\section{Statistical analysis}

Qualitative variables were compared using chi-squared test or Fisher's exact test. The distribution of quantitative variables was tested for normality using Kolmogorov-Smirnov test. Quantitative variables following normal distribution were compared using Student's $t$-test and are expressed using mean value and standard deviation. Quantitative variables not following a normal distribution were analyzed using Mann-Whitney $U$ test and are expressed using median value and 25 th -75 th percentiles. Observed differences were considered statistically significant if $\mathrm{P}$ values were inferior to 0.05. In order to adjust for significant differences between the two groups, a multivariate analysis was performed with microaspiration of gastric or oropharyngeal secretions as dependent variable. Statistical tests were performed using version 15.0 of SPSS software.

\section{Results}

From February 2012 to January 2013, 100 patients were included in the study: 55 patients in the SSD group and 45 patients in the control group.

\section{Patient characteristics}

Baseline characteristics are presented in Table 1. Patients included in the SSD group were significantly less likely to 
Table 1 Patient characteristics at ICU admission

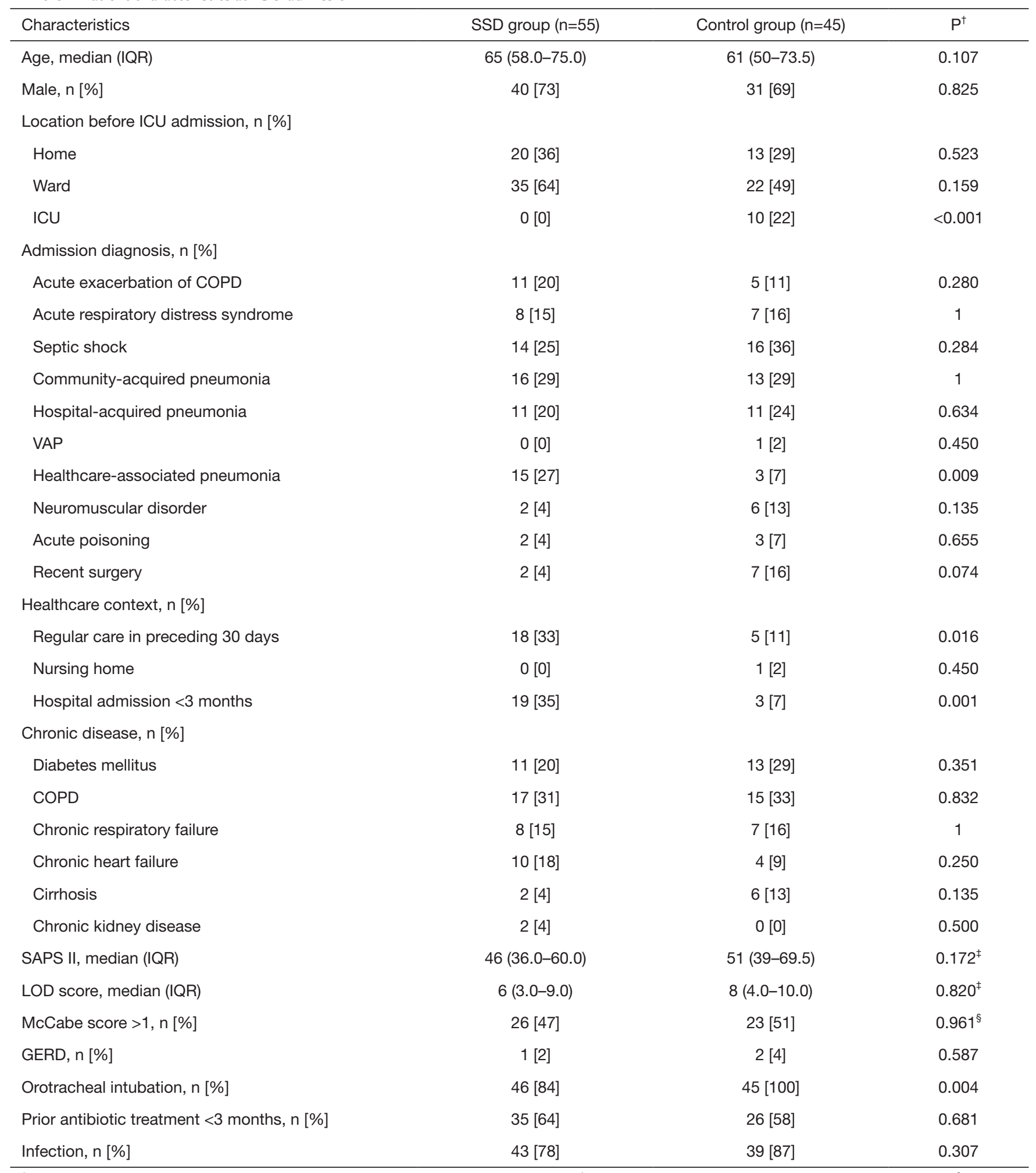

${ }^{\dagger}, \mathrm{P}$ value calculated using Fisher's exact test unless specified otherwise; ${ }^{\ddagger}, \mathrm{P}$ value calculated using Mann-Whitney $\mathrm{U}$ test; ${ }^{\S}$, Linear regression $t$-test. SSD, subglottic secretion drainage; IQR, interquartile range; COPD, chronic obstructive pulmonary disease; SAPS II, simplified acute physiology score II; LOD, logistic organ dysfunction; ICU, intensive care unit. 
Table 2 Patient characteristics in the 24 hours following inclusion

\begin{tabular}{|c|c|c|c|}
\hline Characteristics & SSD group $(n=55)$ & Control group $(n=45)$ & $\mathrm{P}^{\dagger}$ \\
\hline Gastric residual volume $(\mathrm{mL})$, mean $\pm \mathrm{SD}$ & $57 \pm 164$ & $105 \pm 179$ & $0.027^{\ddagger}$ \\
\hline Prokinetic drugs, n [\%] & $2[4]$ & $1[2]$ & $>0.999$ \\
\hline Proton pump inhibitors, $\mathrm{n}[\%]$ & 30 [55] & $23[51]$ & 0.841 \\
\hline Vomiting, $\mathrm{n}[\%]$ & $1[2]$ & $4[9]$ & 0.171 \\
\hline Mean cuff pressure $\left(\mathrm{cmH}_{2} \mathrm{O}\right)$, median (IQR) & $23(21.0-30.0)$ & $29(22.5-30)$ & $0.015^{\ddagger}$ \\
\hline Cuff pressure $<20 \mathrm{cmH}_{2} \mathrm{O}, \mathrm{n}[\%]$ & $20[36]$ & $11[24]$ & 0.277 \\
\hline Sedation, $\mathrm{n}[\%]$ & 27 [49] & $25[56]$ & 0.522 \\
\hline Out-of-ICU transport, n [\%] & $2[4]$ & $1[2]$ & $>0.999$ \\
\hline Prone positioning, $\mathrm{n}$ [\%] & $0[0]$ & $3[7]$ & 0.088 \\
\hline \multicolumn{4}{|l|}{ Ventilation modes ${ }^{\S}, \mathrm{n}[\%]$} \\
\hline Assist-control & $24[44]$ & $27[60]$ & 0.113 \\
\hline Pressure support & 40 [73] & $26[58]$ & 0.140 \\
\hline Biphasic positive airway pressure & $0[0]$ & 1 [2] & 0.450 \\
\hline Mean positive end-expiratory pressure $\left(\mathrm{cmH}_{2} \mathrm{O}\right)$, median (IQR) & $6(5.0-8.0)$ & $8(5.0-10.0)$ & $0.116^{\ddagger}$ \\
\hline
\end{tabular}

${ }^{\dagger}, \mathrm{P}$ value calculated using Fisher's exact test unless specified otherwise; ${ }^{\ddagger}, \mathrm{P}$ value calculated using Mann-Whitney $\mathrm{U}$ test; ${ }^{\S}$, each patient could receive multiple ventilation modes. SSD, subglottic secretion drainage; SD, standard deviation; IQR, interquartile range; ICU, intensive care unit.

be admitted from another ICU, but were significantly more likely to be admitted for healthcare-associated pneumonia, to have received antibiotics or wound care, or to have stayed at a hospital for at least 48 hours in the preceding 3 months. Nasotracheal intubation was only observed in the SSD group ( 9 patients, $16 \%, \mathrm{P}=0.004$ ). There was no difference regarding tracheal tube sizes between groups, with the most frequently used size being 7.5 [25 of 55 (45\%) vs. 25 of 45 (56\%), in SSD and control group, respectively; $\mathrm{P}=0.990$ ].

Although enteral nutrition volume was significantly higher, residual gastric volume and mean cuff pressure were significantly lower in SSD as compared with control group (Table 2). No significant difference was found in other patient characteristics in the $24 \mathrm{~h}$ following inclusion.

\section{Primary and secondary outcomes}

During the 24 hours following inclusion, no significant difference was found in the number of tracheal aspirates performed for pepsin and salivary amylase analyses [4 (2 to 5) in the SSD group vs. 3 (1.5 to 5.5) in the control group, $\mathrm{P}=0.642]$.

No significant difference was found in percentage of patients with microaspiration between the two groups (Table 3). After adjustment for significant differences between the two groups, the rate of patients with microaspiration was still not significantly different between the two groups $(\mathrm{P}=0.586)$. Similarly, no significant difference was found regarding the proportion of tracheal aspirates positive for pepsin or amylase [mean $\pm \mathrm{SD}(81.4 \pm 31.4 \%$ vs. $75.6 \pm 36.6 \%)$, $\mathrm{P}=0.584]$, for pepsin $[0(0-50 \%)$ vs. $0(0-17.8 \%), \mathrm{P}=0.152]$ or for amylase $[88(58.5-100 \%)$ vs. $100(33-100 \%)$, $\mathrm{P}=0.859]$, in SSD and control groups; respectively.

No significant difference was observed in the average pepsin level [median 114 (IQR 62-266) vs. 99 (IQR 52-185) $\mu \mathrm{g} / \mathrm{L}$, $\mathrm{P}=0.389]$ or amylase $[10,675$ (IQR 2,293-79,705) vs. 4,279 
Table 3 Impact of SSD on outcomes

\begin{tabular}{|c|c|c|c|}
\hline Outcomes & SSD group $(n=55)$ & Control group $(n=45)$ & $P^{\ddagger}$ \\
\hline Microaspiration, $\mathrm{n}[\%]$ & 49 [89] & 37 [82] & 0.469 \\
\hline \multicolumn{4}{|l|}{ Secondary outcomes } \\
\hline Microaspiration of gastric contents, $n$ [\%] & 23 [42] & 13 [29] & 0.185 \\
\hline VAP, n [\%] & 16 [29] & $11[24]$ & 0.656 \\
\hline VAT, n [\%] & $7[13]$ & 4 [9] & 0.750 \\
\hline Tracheobronchial colonization, $\mathrm{n}$ [\%] & 15 [35] & $8[18]$ & 0.219 \\
\hline \multicolumn{4}{|l|}{ Other outcomes } \\
\hline MV duration (days), median (IQR) & $10(5.0-18.0)$ & $11(7.0-28.0)$ & $0.158^{\S}$ \\
\hline Duration of antibiotic treatment (days), median (IQR) & $12(8.0-19.0)$ & $10(7.0-22.0)$ & $0.617^{\S}$ \\
\hline
\end{tabular}

(IQR 1,564-55,572) IU/L, $\mathrm{P}=0.357$ ] between SSD and control groups, respectively.

No significant difference was found regarding the percentage of patients with VAP, VAT or tracheobronchial colonization between the two groups. Similarly, no significant difference was found in other outcomes, including duration of MV, ICU length of stay or ICU mortality between the two groups (Table 3).

\section{Discussion}

Our results suggest that SSD is not associated with reduced microaspiration in intubated critically ill patients. No significant difference was found in microaspiration of gastric contents, or oropharyngeal secretions. Furthermore, the percentage of patients with VAT, VAP, or tracheobronchial colonization was not significantly different between patients who received SSD and those who did not.

To our knowledge, our study is the first to evaluate the impact of SSD on microaspiration in critically-ill patients. The strengths of this study include exhaustive epidemiological and potential confounding factor collection, its prospective design, and the combined use of salivary amylase and pepsin for microaspiration assessment.

Some limitations must be outlined. First, the number of included patients was relatively small. Therefore, different results could have been obtained had the number of patients been higher. Second, the observational design resulted in some differences between the two groups. However, after adjustment for significant differences between the two groups, similar results were found regarding the impact of SSD on microaspiration. Third, there was a major difference in tracheal tube cuff design between groups, namely that patients in the SSD group were intubated with tapered cuff tracheal tubes, while patients in the control group were intubated with standard (cylindrical) cuff tracheal tubes. Recent studies showed that tapered cuffed tracheal tubes were associated with significantly higher variations in cuff pressure (24), compared with standard-cuff tracheal tubes. This finding is consistent with the mean cuff pressure observed in our study being significantly lower in the SSD group, compared with control group [23 (21.0-30.0) vs. 29 (22.5-30), $\mathrm{P}=0.015]$ and the higher number of patients showing cuff pressure $<20 \mathrm{cmH}_{2} \mathrm{O}$. Finally, our study was performed in a single center, and its result might not be generalizable to other ICU patients.

Several previous randomized controlled studies reported significant reduction in VAP rates when SSD is used, compared with routine care. Mao et al. recently performed a meta-analysis of 20 randomized controlled trials, including 
3,544 patients (25). SSD decreased VAP incidence and duration of MV and delayed VAP onset. However, this measure did not reduce mortality and length of ICU stay. SSD is recommended for preventing VAP by recent statements of the Intensive Care Society given consistent data on VAP rate reduction in three meta-analyses $(12,14,15,26)$.

\section{Conclusions}

In conclusion, the use of SSD was not associated with a reduction of microaspiration or VAP incidence in our study. Further, large multicenter studies are required to evaluate the impact of SSD on microaspiration in intubated critically-ill patients.

\section{Acknowledgements}

None.

\section{Footnote}

Conflicts of Interest: The authors have no conflicts of interest to declare.

Ethical Statement: For this strictly observational study, no approval was required from the local ethics committee and patients and patients' proxy received written information about participation to this study and could refuse participating or withdraw at any point.

\section{References}

1. Surveillance des infections nosocomiales en réanimation adulte (2017), Rapport de l'Institut de Veille Sanitaire. Available online: http://invs.santepubliquefrance. fr/Publications-et-outils/Rapports-et-syntheses/ Maladies-infectieuses/2017/Surveillance-des-infectionsnosocomiales-en-reanimation-adulte

2. Melsen WG, Rovers MM, Bonten MJM. Ventilatorassociated pneumonia and mortality: a systematic review of observational studies. Crit Care Med 2009;37:2709-18.

3. Nair GB, Niederman MS. Ventilator-associated pneumonia: present understanding and ongoing debates. Intensive Care Med 2015;41:34-48.

4. Koulenti D, Tsigou E, Rello J. Nosocomial pneumonia in 27 ICUs in Europe: perspectives from the EU-VAP/CAP study. Eur J Clin Microbiol Infect Dis 2017;36:1999-2006.
5. Branch-Elliman W, Wright SB, Howell MD. Determining the Ideal Strategy for Ventilator-associated Pneumonia Prevention. Cost-Benefit Analysis. Am J Respir Crit Care Med 2015;192:57-63.

6. American Thoracic Society; Infectious Diseases Society of America. Guidelines for the Management of Adults with Hospital-acquired, Ventilator-associated, and Healthcareassociated Pneumonia. Am J Respir Crit Care Med 2005;171:388-416.

7. Pneumonies associées aux soins de réanimation, Société Française d'Anesthésie et de Réanimation, 2017. Available online: http://sfar.org/pneumonies-associees-aux-soins-dereanimation/

8. Marik PE. Aspiration pneumonitis and aspiration pneumonia. N Engl J Med 2001;344:665-71.

9. Rello J, Soñora R, Jubert P, et al. Pneumonia in intubated patients: role of respiratory airway care. Am J Respir Crit Care Med 1996;154:111-5.

10. Craven DE. Preventing ventilator-associated pneumonia in adults: sowing seeds of change. Chest 2006;130:251-60.

11. Mahul P, Auboyer C, Jospe R, et al. Prevention of nosocomial pneumonia in intubated patients: respective role of mechanical subglottic secretions drainage and stress ulcer prophylaxis. Intensive Care Med 1992;18:20-5.

12. Dezfulian C, Shojania K, Collard HR, et al. Subglottic secretion drainage for preventing ventilator-associated pneumonia: a meta-analysis. Am J Med 2005;118:11-8.

13. Lacherade JC, De Jonghe B, Guezennec P, et al. Intermittent subglottic secretion drainage and ventilatorassociated pneumonia: a multicenter trial. Am J Respir Crit Care Med 2010;182:910-7.

14. Muscedere J, Rewa O, McKechnie K, et al. Subglottic secretion drainage for the prevention of ventilatorassociated pneumonia: a systematic review and metaanalysis. Crit Care Med 2011;39:1985-91.

15. Wang F, Bo L, Tang L, et al. Subglottic secretion drainage for preventing ventilator-associated pneumonia: an updated meta-analysis of randomized controlled trials. J Trauma Acute Care Surg 2012;72:1276-85.

16. Damas P, Frippiat F, Ancion A, et al. Prevention of ventilator-associated pneumonia and ventilator-associated conditions: a randomized controlled trial with subglottic secretion suctioning. Crit Care Med 2015;43:22-30.

17. Caroff DA, Li L, Muscedere J, et al. Subglottic Secretion Drainage and Objective Outcomes: A Systematic Review and Meta-Analysis. Crit Care Med 2016;44:830-40.

18. Abd El-Fattah AM, Maksoud GAA, Ramadan AS, et al. Pepsin assay: A marker for reflux in pediatric glue ear. 
Otolaryngol Head Neck Surg 2007;136:464-70.

19. Dewavrin F, Zerimech F, Boyer A, et al. Accuracy of Alpha Amylase in Diagnosing Microaspiration in Intubated Critically-Ill Patients. PLoS One 2014;9:e90851.

20. Le Gall JR, Lemeshow S, Saulnier F. A New Simplified Acute Physiology Score (SAPS II) Based on a European/North American Multicenter Study. JAMA 1993;270:2957-63.

21. McCabe WR. Gram-Negative Bacteremia: I. Etiology and Ecology. Arch Intern Med 1962;110:847.

22. Le Gall JR, Klar J, Lemeshow S, et al. The Logistic Organ Dysfunction System: A New Way to Assess Organ Dysfunction in the Intensive Care Unit. JAMA 1996;276:802-10.

23. National Nosocomial Infections Surveillance System. National Nosocomial Infections Surveillance (NNIS)

Cite this article as: Millot G, Boddaert P, Parmentier-Decrucq E, Palud A, Balduyck M, Maboudou P, Zerimech F, Wallet F, Preau S, Nseir S. Impact of subglottic secretion drainage on microaspiration in critically ill patients: a prospective observational study. Ann Transl Med 2018;6(21):416. doi: 10.21037/atm.2018.10.44
System Report, data summary from January 1992 through June 2004, issued October 2004. Am J Infect Control 2004;32:470-85.

24. Nseir S, Zerimech F, De Jonckheere J, et al. Impact of polyurethane on variations in tracheal cuff pressure in critically ill patients: a prospective observational study. Intensive Care Med 2010;36:1156-63.

25. Mao Z, Gao L, Wang G, et al. Subglottic secretion suction for preventing ventilator-associated pneumonia: an updated meta-analysis and trial sequential analysis. Crit Care 2016;20:353.

26. Hellyer TP, Ewan V, Wilson P, et al. The Intensive Care Society recommended bundle of interventions for the prevention of ventilator-associated pneumonia. J Intensive Care Soc 2016;17:238-43. 